\title{
Physical activity and obesity in children
}

\author{
Andrew P Hills, ${ }^{1}$ Lars Bo Andersen, ${ }^{2,3}$ Nuala M Byrne ${ }^{4}$
}

${ }^{1}$ Griffith University and Mater Medical Research Institute (MMRI), Brisbane, Queensland, Australia

${ }^{2}$ Department of Exercise Epidemiology, Institute of Sport Sciences and Clinical Biomechanics, University of Southern Denmark, Odense, Denmark

${ }^{3}$ Department of Sports

Medicine, Norwegian School of Sport Sciences, Oslo,

Norway.

${ }^{4}$ Institute of Health and Biomedical Innovation, Queensland University of Technology, Brisbane, Queensland, Australia

\section{Correspondence to}

Professor Andrew P Hills, Griffith Health Institute, Griffith University and Mater Medical Research Institute, Raymond Terrace, South Brisbane, OLD 4101 Australia; a.hills@griffith.edu.au

Accepted 26 June 2011

\begin{abstract}
Globally, obesity is affecting an increasing proportion of children. Physical activity plays an important role in the prevention of becoming overweight and obese in childhood and adolescence, and reducing the risk of obesity in adulthood. Puberty and the following adolescent period are acknowledged as particularly vulnerable times for the development of obesity due to sexual maturation and, in many individuals, a concomitant reduction in physical activity. In many Western settings, a large proportion of children and adolescents do not meet recommended physical activity guidelines and, typically, those who are more physically active have lower levels of body fat than those who are less active. Active behaviours have been displaced by more sedentary pursuits which have contributed to reductions in physical activity energy expenditure. Without appropriate activity engagement there is an increased likelihood that children will live less healthy lives than their parents. Owing to the high risk of overweight adolescents becoming obese adults, the engagement of children and adolescents in physical activity and sport is a fundamental goal of obesity prevention.
\end{abstract}

\section{INTRODUCTION}

The rising prevalence of childhood obesity is a serious concern in developed countries ${ }^{1}$ and increasingly in many parts of the developing world. ${ }^{2}$ It is interesting to note that based on recent data from Sweden, Denmark and Norway, which show that childhood obesity has not worsened since the year 2000, it may be possible to stop the epidemic. ${ }^{4-6}$ The most significant long-term consequence of obesity in childhood is adult obesity and its related comorbidities. ${ }^{7}$ An extensive body of research indicates a higher risk of overweight and obese children becoming obese adults than their normal-weight counterparts ${ }^{8-12}$ and a major contributing factor is low levels of physical activity. Obesity in adolescence also predicts later mortality. ${ }^{13}$

Physical activity is essential for the normal growth and development of children and adolescents, ${ }^{14} 15$ plays an important role in the prevention of becoming overweight and obese in childhood and adolescence, and reduces the health risks of the condition. ${ }^{16}$ However, Western society actively discourages physical activity by decreasing the opportunities to expend energy ${ }^{17}$ and, in many settings, a large proportion of children and adolescents do not meet recommended physical activity guidelines. Evidence also suggests that obese youngsters are less physically active than the non-obese ${ }^{18} 19$ and spend more time in sedentary pursuits, such as watching television and using other electronic media. ${ }^{20} 21$ It is logical to suggest that if such pastimes continue to displace physical activity and exercise, there is an increased risk of children becoming overweight or obese. ${ }^{22}$ Without appropriate involvement in physical activity, there is an increased likelihood that children will live less healthy lives than their parents. ${ }^{23}$ As obesity is already a health risk in childhood because of its association with a clustering of cardiovascular disease (CVD) risk factors and atherosclerosis is believed to progress throughout life, ${ }^{24}$ the engagement of children and adolescents in physical activity and sport is a fundamental goal of obesity prevention.

This review provides an overview of the relationship between physical activity and obesity in children. Physical and psychosocial health problems associated with excess body fat are highlighted, along with a consideration of the key determinants of obesity. If childhood obesity is to be reduced, greater attention needs to be paid to opportunities for all youngsters, irrespective of size and shape, to engage in physical activity and sport.

\section{OBESITY AND PHYSICAL HEALTH PROBLEMS}

A number of potential health consequences are associated with excess body fat during the growing years and, without effective intervention, the risk of ill health escalates throughout the adult years. ${ }^{22}$ Health problems may include CVD and metabolic, gastrointestinal, pulmonary, orthopaedic, neurological, psychological and social disorders. ${ }^{2526}$ Specific examples include a predisposition to type 2 diabetes and liver disease, and risk factors for CVD, asthma, sleep apnoea and impaired mobility. ${ }^{17}$ Andersen et a ${ }^{24} 27$ have referenced the clustering of risk factors in this population, along with lower levels of physical activity, as causes. A recent paper ${ }^{25}$ suggested that there may not be a direct relationship between childhood obesity and cardiovascular risk factors in adulthood but instead an indirect relationship through the tracking of obesity from childhood to adulthood.

\section{OBESITY AND PSYCHOSOCIAL HEALTH PROBLEMS}

In addition to short- and long-term physical health problems, obese children and adolescents are likely to suffer poorer psychological ${ }^{28}$ and social health than their normal-weight peers (low self-esteem and self-concept, ${ }^{29}$ reduced quality of life, ${ }^{30-32}$ depression ${ }^{1}$ and social discrimination).

\section{SUSCEPTIBILITY AND PREDISPOSITION TO OBESITY}

Being overweight and obese results from an energy imbalance; a disruption between energy consumed in food and drink and energy expended in physical activity and exercise. The steady increase in 
overweight children and childhood obesity in recent decades may be the result of an increase in energy intake, a decrease in energy expenditure or, more logically, a combination of both. Obesity is further complicated by the complex interaction between diet, physical activity and metabolic and genetic factors $^{33}$ in an environment that encourages consumption of high-energy foods and discourages expenditure of energy. ${ }^{34}$ Although genetic or transmissible factors account for much of the individual variability in body size and shape and influence one's propensity to manage body weight, ${ }^{35}$ the major environmental contributor to an increase in fat deposition is a positive energy balance. ${ }^{3637}$ It is important to highlight that one of the main effects of physical activity is not energy expenditure per se, but rather the effect it has on improved appetite regulation.

A complex set of individual, family- and community-level factors affect weight status in children and influence children's decision-making regarding energy intake and expenditure. ${ }^{1}$ Many of the factors that account for the significant recent increases in the prevalence of obesity may have also changed over time. ${ }^{38}$ These include an increase in the perceived risks of physical activity and sports participation, changes to the physical environment, a scarcity of time, prioritising academic versus more active pursuits, and, potentially, cost. ${ }^{17} 3940$ Similarly, the value people place on physical activity and exercise may also have changed over time. Changes in societal attitudes about body size and shape and body image may have also influenced physical activity practices; for example, there is an increased polarisation of the population to more obese and very lean children. ${ }^{41}$

One of the useful frameworks presented to conceptualise the many factors associated with childhood obesity was developed by Davison and Birch. ${ }^{42}$ The framework includes three main categories:

Child characteristics and behaviours: genetic predisposition plus energy intake, physical activity and sedentary behaviours

Parenting styles and family characteristics: influence children's behaviour

Community, demographic and societal characteristics: influence the behaviours of children, parents and families. Includes socioeconomic status, education, ethnicity, advertising and the physical environment.

\section{PHYSICAL ACTIVITY AND OBESITY}

Physical activity, and diet, are the cornerstones of obesity prevention and management. ${ }^{43}$ Optimal nutrition in combination with regular physical activity during the growing years increases the likelihood of a healthy pattern of physical maturation consistent with the genetic potential of an individual child. ${ }^{14} 39$ Physical activity is beneficial at all stages during the formative years and active play is important in physical, mental and social aspects of growth and development, ${ }^{14} 15$ helping to set a pattern of participation in physical activity across the lifespan. ${ }^{44}$

A range of environmental factors including less active transport ${ }^{45}$ and the changing nature of school-ground facilities ${ }^{46}$ have resulted in the reduction or removal of many physical activities from our contemporary lifestyle and thereby contributed to the childhood obesity epidemic. ${ }^{47}$ Levels of habitual physical activity in many young people and adults are lower than they were in the past ${ }^{48}$ and this has contributed to both a reduction in physical activity energy expenditure and, as a consequence, total energy expenditure. ${ }^{36} 49$ Accordingly, normal levels of habitual physical activity are lower than required to maintain a healthy body weight. ${ }^{43}$

Despite acknowledged challenges in the objective assessment of physical activity in children, there is evidence that many young people participate in considerably less physical activity than is recommended for health. ${ }^{50} 51$ Of particular concern is that physical activity levels decline in the period of transition from childhood to adolescence, between the ages of 9 and 15 years. ${ }^{52}$

Despite data on the relationship between physical activity and obesity in children and adolescents being inconsistent, ${ }^{12}$ most studies of habitual physical activity in children suggest that the overweight and obese are less active $e^{14165354}$ and have poorer fundamental movement skills than their normal-weight counterparts. ${ }^{55}$ There is also consistent evidence that boys are more habitually active than girls and even at the age of 6 years boys have lower skinfold thickness, ${ }^{56-58}$ and that obese children favour participation in sedentary behaviours. ${ }^{59}$

Low levels of physical activity during childhood combined with obesity contribute to substandard health-related fitness ${ }^{47}$ and reduced confidence in the ability of such children to participate in sport and physical activity. In contrast, enhancement of motor skills has the potential to improve a child's motivation to participate in physical activity through improved selfesteem and increased enjoyment. ${ }^{60}$

Physical activity has a direct relationship with the healthy weight status of children through higher levels of energy expenditure. However, physical activity level is also directly associated with health outcomes of children; low levels of physical activity are typically associated with an increased risk of cardiometabolic and vascular diseases. ${ }^{16}$ Therefore, encouraging both normal-weight and overweight children to increase their levels of physical activity and exercise and reduce their sitting time will help to avoid excess weight gain and associated health risks. ${ }^{61}$

In adults, physical inactivity and obesity have similar health consequences. ${ }^{62}$ Importantly, obese individuals who are physically active may have lower morbidity and mortality than their normal-weight but sedentary counterparts. A recent systematic review of adult studies by Fogelholm ${ }^{63}$ indicated that the risk for all-cause and cardiovascular mortality was lower in individuals with high body mass index (BMI) and good aerobic fitness, compared with individuals with normal BMI and poor fitness. In contrast, individuals with a high BMI, even with high physical activity, have a greater risk for the incidence of type 2 diabetes and the prevalence of cardiovascular and diabetes risk factors, compared with individuals with a normal BMI and low physical activity.

Fogelholm ${ }^{63}$ proposed two major links between physical activity and obesity. First, physical activity may prevent weight gain by increasing daily energy expenditure and potentially by suppressing appetite. A common finding in cross-sectional studies is the association between lower prevalence of obesity and higher physical activity. ${ }^{64}$ This finding contrasts with the inconclusive findings reported in intervention studies. ${ }^{65}$ An explanation for the strong association between physical activity and obesity in cross-sectional studies is 'reciprocal causality' such that physical activity enables individuals to control their weight easier by increasing energy expenditure. In contrast, unsuccessful weight control reduces aerobic fitness, increases musculo-skeletal pain and increases discomfort, which results in physical activity being more challenging. Health is the second major link between physical activity and obesity cited by Fogelholm, ${ }^{63}$ including risk of CVDs, type 2 
diabetes and some cancers. ${ }^{66}$ Most importantly, each of the health risks is reduced by adequate levels of physical activity and at least moderate cardiorespiratory fitness. ${ }^{67}$

Physical activity and fitness in childhood and adolescence is also associated with numerous health benefits, ${ }^{68-71}$ despite being deficient in many settings. ${ }^{72}$ Appropriate levels of physical activity can confer fitness while lowering the risk of obesity and health risks associated with increased fatness. ${ }^{63} 7374$ Physical activity also contributes to greater bone density, ${ }^{75}$ reduced clustering of CVD risk factors, ${ }^{7677}$ improvement in body composition and assists in maintenance of weight loss. ${ }^{78}$

Improvements in our understanding of the factors that contribute to excess weight gain stems from the tracking of adiposity and lifestyle behaviours from infancy through childhood, adolescence and into adulthood. ${ }^{79-81}$ Between 2 and 5 years of age, overweight children have four times the risk of normal-weight children of being overweight as adults ${ }^{82}$ and the strength of the association increases throughout the growing years. ${ }^{13}$

There is growing evidence that the health of children in most Western countries has deteriorated in recent decades. Consistent with this trend is the increased prevalence of childhood overweight and obesity, declines in physical performance and more youngsters with very low fitness. Paradoxically, indications from the literature are that children and adolescents in many countries are sufficiently active. However, much of this evidence is based on self-reported physical activity data and there is a paucity of national data in many countries, including Australia. Based on objective measures, Colley et a ${ }^{83}$ recently reported that physical activity levels of Canadian children and youth are very low. In Australia, numerous studies have reported reductions in active transport in 5-14-year-old children between 1971 and 2003,84 and significantly lower levels of moderate- to vigorous-intensity physical activity. 8586 Further, examinations of the relationship between physical activity and childhood obesity have reported significant inverse associations between physical activity levels, BMI and body fat. 8788

Despite the need for more evidence, it is critical that all children and adolescents accumulate sufficient physical activity each day. The recent WHO global recommendation on physical activity for health recommends children and adolescents aged 5-17 years participate in at least 60 min of moderate- to vigorous-intensity physical activity every day. ${ }^{89}$ Most importantly, the recommendation acknowledges that this volume of exercise must be in addition to the activities of daily living, calculated using objective measures as 35-40 min moderate- to vigorous physical activity ${ }^{70}$ This recommendation is consistent with other countries including Australia, ${ }^{90} 91$ the $\mathrm{UK}^{92}$ and Canada. ${ }^{83} 93$ Martinez-Gomez et a ${ }^{94}$ have recently reported that current physical activity guidelines appear to be appropriate to prevent the accumulation of excess body fat in European adolescents. Like Gutin, ${ }^{95}$ they suggest that for obesity prevention, greater attention be paid to participation in vigorous intensity physical activity.

\section{CONCLUSIONS}

In conclusion, there appears to be a strong relationship between physical activity and obesity in children and adolescents. Physical activity in children and youths is associated with health benefits, ${ }^{96}$ including lower levels of being overweight and obese. Higher levels of activity translate into greater benefits. ${ }^{83}$ Although many reports suggest that children's participation in organised sport and physical activity has increased, incidental physical activity and exercise, including active transport such as walking to and from school, has declined. Similarly, there is weak evidence for the effectiveness of interventions to prevent childhood obesity. This may be due to a range of factors including inconsistent approaches used in systematic reviews, disparities in anthropometric approach, and whether body fat was predicted or measured objectively. Reilly ${ }^{97}$ has suggested that the ineffectiveness of many obesity interventions relates to targeting behaviour modification at the level of the individual, children, their families or schools, whereas many influences on weight status are broader and include education, food labelling, taxes and transport, as outlined by Nestle et al. ${ }^{9899}$ From a public health perspective, the promotion of a healthy diet and the encouragement of physical activity and exercise are equally important factors for the maintenance of a healthy weight and body composition and reducing the risk of chronic diseases. ${ }^{100}$

Contributors Contributors provided equally in the preparation of the manuscript. Competing interests None.

Provenance and peer review Not commissioned; externally peer reviewed.

\section{REFERENCES}

1. Lobstein T, Baur L, Uauy R. Obesity in children and young people: a crisis in public health. Obes Rev 2004;5(Suppl 1):4-104.

2. Wang $\mathbf{Y}$, Lobstein T. Worldwide trends in childhood overweight and obesity. Int J Pediatr Obes 2006;1:11-25.

3. Kelishadi R. Childhood overweight, obesity, and the metabolic syndrome in developing countries. Epidemiol Rev 2007;29:62-76.

4. Pearson S, Hansen B, Sørensen TI, et al. Overweight and obesity trends in Copenhagen schoolchildren from 2002 to 2007. Acta Paediatr 2010;99:1675-8.

5. Lissner L, Sohlström A, Sundblom E, et al. Trends in overweight and obesity in Swedish schoolchildren 1999-2005: has the epidemic reached a plateau? Obes Rev 2010;11:553-9

6. Kolle E, Steene-Johannessen J, Holme I, et al. Secular trends in adiposity in Norwegian 9-year-olds from 1999-2000 to 2005. BMC Public Health 2009;9:389.

7. World Health Organization. Obesity: Preventing and Managing the Global Epidemic. Report of a WHO Consultation, WHO Technical Report Series No. 894. Geneva: WHO, 2000.

8. Boreham C, Robson PJ, Gallagher AM, et al. Tracking of physical activity, fitness, body composition and diet from adolescence to young adulthood: The Young Hearts Project, Northern Ireland. Int J Behav Nutr Phys Act 2004;1:14.

9. Daniels SR, Jacobson MS, McCrindle BW, et al. American Heart Association Childhood Obesity Research Summit Report. Circulation 2009;119:e489-517.

10. Singh AS, Mulder C, Twisk JW, et al. Tracking of childhood overweight into adulthood: a systematic review of the literature. Obes Rev 2008;9:474-88

11. Mamun AA, Hayatbakhsh MR, O'Callaghan M, et al. Early overweight and pubertal maturation - pathways of association with young adults' overweight: a longitudinal study. Int J Obes (Lond) 2009;33:14-20.

12. Venn AJ, Thomson RJ, Schmidt MD, et al. Overweight and obesity from childhood to adulthood: a follow-up of participants in the 1985 Australian Schools Health and Fitness Survey. Med J Aust 2007;186:458-60.

13. Baker JL, Olsen LW, Sørensen TI. Childhood body-mass index and the risk of coronary heart disease in adulthood. N Engl J Med 2007;357:2329-37.

14. Hills AP, King NA, Armstrong TP. The contribution of physical activity and sedentary behaviours to the growth and development of children and adolescents: implications for overweight and obesity. Sports Med 2007;37:533-45.

15. Hills AP, Okely AD, Baur LA. Addressing childhood obesity through increased physical activity. Nat Rev Endocrinol 2010;6:543-9.

16. Strong WB, Malina RM, Blimkie CJ, et al. Evidence based physical activity for school-age youth. J Pediatr 2005;146:732-7.

17. Ludwig DS, Pollack HA. Obesity and the economy: from crisis to opportunity. JAMA 2009;301:533-5.

18. Janssen I, Katzmarzyk PT, Boyce WF, et al. Overweight and obesity in Canadian adolescents and their associations with dietary habits and physical activity patterns. J Adolesc Health 2004;35:360-7.

19. Vandewater EA, Shim MS, Caplovitz AG. Linking obesity and activity level with children's television and video game use. J Adolesc 2004;27:71-85.

20. Caroli M, Argentieri L, Cardone M, et al. Role of television in childhood obesity prevention. Int J Obes Relat Metab Disord 2004;28(Suppl 3):S104-8.

21. Hesketh K, Wake M, Graham M, et al. Stability of television viewing and electronic game/computer use in a prospective cohort study of Australian children: relationship with body mass index. Int J Behav Nutr Phys Act 2007;4:60. 
22. Must A, Strauss RS. Risks and consequences of childhood and adolescent obesity. Int J Obes Relat Metab Disord 1999;23(Suppl 2):S2-11.

23. Olshansky SJ, Passaro DJ, Hershow RC, et al. A potential decline in life expectancy in the United States in the 21st century. N Engl J Med 2005:352:1138-45.

24. Andersen LB, Sardinha LB, Froberg K, et al. Fitness, fatness and clustering of cardiovascular risk factors in children from Denmark, Estonia and Portugal: the European Youth Heart Study. Int J Pediatr Obes 2008;3(Suppl 1):58-66.

25. Lloyd LJ, Langley-Evans SC, McMullen S. Childhood obesity and adult cardiovascular disease risk: a systematic review. Int J Obes (Lond) 2010;34:18-28.

26. Steene-Johannessen J, Kolle E, Reseland JE, et al. Waist circumference is related to low-grade inflammation in youth. Int J Pediatr Obes 2010;5:313-19.

27. Andersen LB, Wedderkopp N, Hansen HS, et al. Biological cardiovascular risk factors cluster in Danish children and adolescents: the European Youth Heart Study. Prev Med 2003;37:363-7.

28. Fox KR. Childhood obesity and the role of physical activity. $J$ R Soc Promot Health 2004:124:34-9.

29. Wardle J, Cooke L. The impact of obesity on psychological well-being Best Pract Res Clin Endocrinol Metab 2005;19:421-40.

30. Schwimmer JB, Burwinkle TM, Varni JW. Health-related quality of life of severely obese children and adolescents. JAMA 2003;289:1813-19.

31. Fallon EM, Tanofsky-Kraff M, Norman AC, et al. Health-related quality of life in overweight and nonoverweight black and white adolescents. J Pediatr 2005:147:443-50.

32. Tsiros MD, Olds T, Buckley JD, et al. Health-related quality of life in obese children and adolescents. Int J Obes (Lond) 2009:33:387-400.

33. Pietrobelli A, Malavolti M, Battistini NC, et al. Metabolic syndrome: a child is not a small adult. Int J Pediatr Obes 2008;3(Suppl 1):67-71.

34. Bouchard C. Defining the genetic architecture of the predisposition to obesity: a challenging but not insurmountable task. Am J Clin Nutr 2010;91:5-6.

35. Bouchard C. The biological predisposition to obesity: beyond the thrifty genotype scenario. Int J Obes (Lond) 2007;31:1337-9.

36. Schoeller DA. The energy balance equation: looking back and looking forward are two very different views. Nutr Rev 2009;67:249-54.

37. Woodruff SJ, Hanning RM, Barr SI. Energy recommendations for normal weight, overweight and obese children and adolescents: are different equations necessary? Obes Rev 2009;10:103-8.

38. Malina RM, Little BB. Physical activity: the present in the context of the past. Am J Hum Biol 2008;20:373-91.

39. Sallis JF, Glanz K. Physical activity and food environments: solutions to the obesity epidemic. Milbank 0 2009;87:123-54

40. Hill J0, Peters JC. Environmental contributions to the obesity epidemic. Science 1998;280:1371-4

41. Møller NC, Wedderkopp N, Kristensen PL, et al. Secular trends in cardiorespiratory fitness and body mass index in Danish children: The European Youth Heart Study. Scand J Med Sci Sports 2007:17:331-9.

42. Davison KK, Birch LL. Childhood overweight: a contextual model and recommendations for future research. Obes Rev 2001:2:159-71.

43. Hills AP, Byrne NM. State of the science: a focus on physical activity. Asia Pac J Clin Nutr 2006;15(Suppl):40-8.

44. Huang JS, Sallis J, Patrick K. The role of primary care in promoting children's physical activity. Br J Sports Med 2009;43:19-21.

45. Bere $\mathbf{E}$, Andersen LB. Why no support for an association between active commuting to school and weight status in the literature? J Phys Act Health 2009; 6:533-4

46. Nielsen G, Bugge A, Hermansen B, et al. School ground facilities as a determinant of children's daily activity - a cross-sectional study of Danish primary school children. J Phys Act Health 2011; (In Press).

47. Biddle SJ, Gorely T, Stensel DJ. Health-enhancing physical activity and sedentary behaviour in children and adolescents. J Sports Sci 2004;22:679-701.

48. Sisson SB, Katzmarzyk PT. International prevalence of physical activity in youth and adults. Obes Rev 2008;9:606-14.

49. Brownson RC, Boehmer TK, Luke DA. Declining rates of physical activity in the United States: what are the contributors? Annu Rev Public Health 2005;26:421-43.

50. Reilly JJ, Jackson DM, Montgomery C, et al. Total energy expenditure and physical activity in young Scottish children: mixed longitudinal study. Lancet 2004;363:211-12.

51. Riddoch CJ, Mattocks C, Deere K, et al. Objective measurement of levels and patterns of physical activity. Arch Dis Child 2007:92:963-9.

52. Nader PR, Bradley RH, Houts RM, et al. Moderate-to-vigorous physical activity from ages 9 to 15 years. JAMA 2008;300:295-305.

53. Trost SG, Kerr LM, Ward DS, et al. Physical activity and determinants of physical activity in obese and non-obese children. Int J Obes Relat Metab Disord 2001;25:822-9.

54. Planinsec $\mathbf{J}$, Matejek C. Differences in physical activity between nonoverweight, overweight and obese children. Coll Antropol 2004;28:747-54.
55. Okely AD, Booth ML, Chey T. Relationships between body composition and fundamental movement skills among children and adolescents. Res Q Exerc Sport 2004:75:238-47.

56. Trudeau F, Laurencelle L, Tremblay J, et al. Daily primary school physical education: effects on physical activity during adult life. Med Sci Sports Exerc 1999;31:111-17.

57. Sleap M, Tolfrey K. Do 9- to 12 yr-old children meet existing physical activity recommendations for health? Med Sci Sports Exerc 2001;33:591-6.

58. Eiberg S, Hasselstrom H, Grønfeldt V, et al. Maximum oxygen uptake and objectively measured physical activity in Danish children 6-7 years of age: the Copenhagen school child intervention study. Br J Sports Med 2005; 39:725-30.

59. Marshall SJ, Biddle SJ, Gorely T, et al. Relationships between media use, body fatness and physical activity in children and youth: a meta-analysis. Int J Obes Relat Metab Disord 2004;28:1238-46.

60. Southall JE, Okely AD, Steele JR. Actual and perceived competence in overweight and non-overweight children. Pediatr Exerc Sci 2004;16:15-24.

61. Barnett LM, Morgan PJ, van Beurden E, et al. Perceived sports competence mediates the relationship between childhood motor skill proficiency and adolescent physical activity and fitness: a longitudinal assessment. Int J Behav Nutr Phys Act 2008;5:40.

62. Blair SN, Church TS. The fitness, obesity, and health equation: is physical activity the common denominator? JAMA 2004;292:1232-4.

63. Fogelholm M. Physical activity, fitness and fatness: relations to mortality, morbidity and disease risk factors. A systematic review. Obes Rev 2010;11:202-21.

64. Dwyer T, Hosmer D, Hosmer T, et al. The inverse relationship between number of steps per day and obesity in a population-based sample: the AusDiab study. Int J Obes (Lond) 2007;31:797-804.

65. Fogelholm M, Kukkonen-Harjula K. Does physical activity prevent weight gain a systematic review. Obes Rev 2000;1:95-111.

66. Allender S, Rayner M. The burden of overweight and obesity-related ill health in the UK. Obes Rev 2007:8:467-73.

67. Blair SN, Cheng Y, Holder JS. Is physical activity or physical fitness more important in defining health benefits? Med Sci Sports Exerc 2001;33:S379-99.

68. Ortega FB, Ruiz JR, Castillo MJ, et al. Physical fitness in childhood and adolescence: a powerful marker of health. Int J Obes (Lond) 2008;32:1-11.

69. Ruiz JR, Castro-Piñero J, Artero EG, et al. Predictive validity of health-related fitness in youth: a systematic review. Br J Sports Med 2009;43:909-23.

70. Ortega FB, Artero EG, Ruiz JR, et al. Physical fitness levels among European adolescents: the HELENA study. Br J Sports Med 2011;45:20-9.

71. Kristensen PL, Moeller NC, Korsholm L, et al. The association between aerobic fitness and physical activity in children and adolescents: the European youth heart study. Eur J Appl Physiol 2010;110:267-75.

72. Knuth AG, Hallal PC. Temporal trends in physical activity: a systematic review. J Phys Act Health 2009;6:548-59.

73. Hamer M, O'Donovan G. Cardiorespiratory fitness and metabolic risk factors in obesity. Curr Opin Lipidol 2010;21:1-7.

74. Ness AR, Leary SD, Mattocks $\mathrm{C}$, et al. Objectively measured physical activity and fat mass in a large cohort of children. PLoS Med 2007;4:e97.

75. Hind K, Burrows M. Weight-bearing exercise and bone mineral accrual in children and adolescents: a review of controlled trials. Bone 2007:40:14-27.

76. Andersen LB, Harro M, Sardinha LB, et al. Physical activity and clustered cardiovascular risk in children: a cross-sectional study (The European Youth Heart Study). Lancet 2006;368:299-304.

77. Ferreira I, Boreham CA, Twisk JW, et al. Clustering of metabolic syndrome risk factors and arterial stiffness in young adults: the Northern Ireland Young Hearts Project. J Hypertens 2007;25:1009-20.

78. Jakicic JM. The effect of physical activity on body weight. Obesity (Silver Spring) 2009;17(Suppl 3):S34-8.

79. Olstad DL, McCargar L. Prevention of overweight and obesity in children under the age of 6 years. Appl Physiol Nutr Metab 2009;34:551-70.

80. Magarey AM, Daniels LA, Boulton TJ, et al. Predicting obesity in early adulthood from childhood and parental obesity. Int J Obes Relat Metab Disord 2003;27:505-13.

81. Lanigan J, Singhal A. Early nutrition and long-term health: a practical approach. Proc Nutr Soc 2009;68:422-9.

82. Freedman DS, Khan LK, Serdula MK, et al. The relation of childhood BMI to adult adiposity: the Bogalusa Heart Study. Pediatrics 2005;115:22-7.

83. Colley RC, Garriguet D, Janssen I, et al. Physical activity of Canadian children and youth: accelerometer results from the 2007 to 2009 Canadian Health Measures Survey. Health Rep 2011;22:1-9.

84. van der Ploeg HP, Merom D, Corpuz G, et al. Trends in Australian children traveling to school 1971-2003: burning petrol or carbohydrates? Prev Med 2008:46:60-2.

85. Cleland V, Crawford D, Baur LA, et al. A prospective examination of children's time spent outdoors, objectively measured physical activity and overweight. Int J Obes (Lond) 2008;32:1685-93. 
86. Ball K, Cleland VJ, Timperio AF, et al. Socioeconomic position and children's physical activity and sedentary behaviors: Iongitudinal findings from the CLAN study. J Phys Act Health 2009;6:289-98.

87. Abbott RA, Davies PS. Habitual physical activity and physical activity intensity: their relation to body composition in 5.0-10.5-y-old children. Eur J Clin Nutr 2004;58:285-91.

88. Ball EJ, O'Connor J, Abbott R, et al. Total energy expenditure, body fatness, and physical activity in children aged 6-9 y. Am J Clin Nutr 2001;74:524-8.

89. World Health Organization. Global Recommendations for Physical Activity and Health. Geneva: WHO, 2010.

90. Department of Health and Ageing. Australia's Physical Activity Recommendations for 5-12 Year olds, Commonwealth of Australia, 2004. http://www.health.gov. au/internet/main/publishing.nsf/ (accessed 20 Jul 2011).

91. Department of Health and Ageing. Australia's Physical Activity Recommendations for 12-18 year olds, Commonwealth of Australia, 2004. http://www.health.gov. au/internet/main/publishing.nsf/ (accessed 20 Jul 2011).

92. O'Donovan G, Blazevich AJ, Boreham C, et al. The ABC of Physical Activity for Health: a consensus statement from the British Association of Sport and Exercise Sciences. J Sports Sci 2010;28:573-91.
93. Janssen I. Physical activity guidelines for children and youth. Can J Public Health 2007;98(Suppl 2):S109-21.

94. Martinez-Gomez D, Ruiz JR, Ortega FB, et al. Recommended levels of physical activity to avoid an excess of body fat in European adolescents: the HELENA Study. Am J Prev Med 2010;39:203-11.

95. Gutin B. Child obesity can be reduced with vigorous activity rather than restriction of energy intake. Obesity (Silver Spring) 2008;16:2193-6.

96. Janssen I, Leblanc AG. Systematic review of the health benefits of physical activity and fitness in school-aged children and youth. Int J Behav Nutr Phys Act 2010;7:40.

97. Reilly JJ. Obesity in childhood and adolescence: evidence based clinical and public health perspectives. Postgrad Med J 2006;82:429-37.

98. Nestle M, Jacobson MF. Halting the obesity epidemic: a public health policy approach. Public Health Rep 2000;115:12-24.

99. Nestle M. Strategies to prevent childhood obesity must extend beyond school environments. Am J Prev Med 2010;39:280-1.

100. Ding EL, Hu FB. Commentary: Relative importance of diet vs physical activity for health. Int J Epidemiol 2010;39:209-11. 
BJSM

\section{Physical activity and obesity in children}

Andrew P Hills, Lars Bo Andersen and Nuala M Byrne

Br J Sports Med 2011 45: 866-870

doi: 10.1136/bjsports-2011-090199

Updated information and services can be found at:

http://bjsm.bmj.com/content/45/11/866.full.html

These include:

References This article cites 95 articles, 17 of which can be accessed free at: http://bjsm.bmj.com/content/45/11/866.full.html\#ref-list-1

Email alerting Receive free email alerts when new articles cite this article. Sign up in service the box at the top right corner of the online article.

Notes

To request permissions go to:

http://group.bmj.com/group/rights-licensing/permissions

To order reprints go to:

http://journals.bmj.com/cgi/reprintform

To subscribe to BMJ go to:

http://group.bmj.com/subscribe/ 